\section{Cartografías de lo cotidiano: usos, relatos y disposiciones del espacio en el contexto de la industria minera y textil del Gran Concepción (1940-1973)*}

Cartographies of the everyday: uses, stories and spatial arrangements in the context of the mining and textile industry of Gran Concepción (1940-1973)

\section{Rodrigo GaNTER * \\ AlejandRa Brito ${ }^{* * *}$}

\section{Resumen}

El objetivo es problematizar sociohistóricamente las relaciones entre paternalismo industrial, vínculos sociales y sus efectos en

\footnotetext{
Este artículo forma parte de las investigaciones CONICYT siguientes: Fondecyt 1140461, Fondap 15110020 y PIA Soc1403.

** Universidad de Concepción, Código postal 4070386, rganter@udec.cl

*** Universidad de Concepción, Código postal 4070386, abrito@udec.cl
}

la espacialización de dichos procesos. Los casos corresponden a la industria textil y carbonífera del Gran Concepción 1940 - 1973. La metodología incluyó producción de relatos colectivos y mapeo participativo. Se discuten los hallazgos sobre la colonización de la vida cotidiana de los trabajadores por parte de la industria, evidenciando un diseño ideológico de sus barrios y la gestión del ocio. Ambos procesos afianzan el modelo disciplinario más vertical, innovando con componentes simbólicos, afectivos y culturales para el control más difuso de la clase trabajadora.

Palabras clave: Paternalismo industrial, Memoria colectiva, Subjetividad espacial, Barrios obreros, Gestión del ocio.

\begin{abstract}
The article discusses, from a socio-historical view, the relationships between industrial paternalism and social ties, and their spatial effects. The cases correspond to the textile and coal industry of the city of Concepción 1945 - 1973. The methodology includes collective stories and participatory mapping. Findings concerning the industrial colonization of worker's daily life are discussed, showing an ideological design of neighbourhoods and leisure management. Both processes strengthen the vertical disciplinary model, innovating with symbolic, emotional and cultural components to a more diffuse control of the working-class.
\end{abstract}

Key words: Industrial Paternalism, Collective Memory, Space Subjectivity, Working-class neighbourhoods, Leisure Management. 


\section{Trayectos e inflexiones de la mirada}

El siguiente texto forma parte de una investigación más amplia sobre Industrialización, relaciones sociales y espacio en contexto del Gran Concepción, durante el período 19401973. Nos interesa problematizar las relaciones entre las fábricas estratégicas de la zona y las políticas de bienestar dirigidas hacia los trabajadores en el contexto del paternalismo industrial, particularmente las políticas vinculadas con la configuración del espacio y la gestión de ocio. Para dicho efecto se presentan los principales hallazgos generados para el caso de la industria textil en la comuna de Tomé y de la industria carbonífera en la comuna de Coronel, ambas surgidas a mediados del siglo XIX. Lo anterior a partir de la combinación de metodologías participativas, como el mapeo colectivo, y las de carácter dialógico, como la producción de talleres para la reconstrucción de la memoria colectiva de los trabajadores ${ }^{1}$. Desde un punto de vista epistemológico, nos situamos en un el ámbito interdisciplinario, y nuestro enfoque articula el diálogo entre la historia social, el llamado giro espacial, la sociología urbana y la geografía crítica.

Los talleres se realizaron durante el segundo semestre del 2014, incluyendo la producción de 2 talleres en Bellavista, comuna de Tomé y 2 talleres en Puchoco, comuna de Coronel. En las sesiones participaron un total de 37 residentes fundadores de los barrios vinculados con las industrias, con un total promedio de 2,5 horas por cada una de las sesiones; y fueron coordinados e implementados por los investigadores que encabezan el estudio junto a un equipo de asistentes. Las conversaciones fueron registradas mediante medios digitales y audiovisuales. Las dinámicas incluyeron tanto el trabajo in situ con mapas interactivos como la producción de relatos colectivos -de mujeres y varones- sobre la vida cotidiana en las industrias y los barrios.

\subsection{Paternalismo Industrial}

El paternalismo se instala como una práctica en los centros industriales, reconociendo la necesidad de transformar la mano de obra de carácter peonal-propia del modo de producción colonial $^{2}-$ caracterizada por la movilidad masculina y sin la disciplina que requerían los sistemas industriales. Tempranamente se evidenció -como lo hicieron los patrones industriales europeos ${ }^{3}$ - que era necesario controlar el adentro y el afuera de la fábrica. Ante la ausencia de una política social de carácter estatal, impensable bajo el modelo liberal existente, fueron los propios patronos industriales quienes se dieron la tarea de moralizar al trabajador y su familia, a fin de convertirlos en mejores agentes productivos y reproductivos; de este modo, "las prácticas paternalistas se sitúan a medio camino del trabajo y del no-trabajo, en el centro de un haz de flujos que relaciona la reproducción con la producción, el trabajo del obrero con su vida" (Sierra 1990: 6). Se generaba, así, una relación más allá del salario, que posibilitaba construir lazos en el tiempo y fijar a los trabajadores y a sus familias, asegurando la reproducción de la mano de obra. Existió una acción deliberada de mantener un vínculo sólido entre trabajo y familia, convirtiéndose esta última en un eje articulador de los mecanismos disciplinadores, como plantea Sennet "Ios paternalistas empresariales trataron de soldar simbólicamente la familia y el trabajo mediante imágenes de sí mismos como autoridades. Al hacerlo aspiraban a la cohesión

Mayor información en Salazar, G. 1985. Labradores, peones y proletarios. Formación y crisis de la sociedad popular chilena del siglo XIX. Santiago: SUR Ediciones.

El análisis sobre la situación que se vive en Europa y particularmente en España sobre patronos industriales e implementación del paternalismo industrial en Sierra, J. 1990. El obrero soñado. Ensayo sobre el paternalismo industrial (Asturias, 1800-1917). Madrid: Siglo XXI Editores. 
comunal y a extraer de esta comunidad estable de trabajadores tasas más elevadas de productividad" (1982: 65).

Las políticas implementadas logran suavizar a través de una nutrida política de beneficios sociales, la falta de regulación del trabajo, construyendo además espacios cerrados, una especie de microcosmos que permite el control más efectivo. Lo que se busca es una transformación más profunda, de allí que las preocupaciones se hicieran extensivas a todos los ámbitos de la vida $y$,

\begin{abstract}
(...) comiencen a preocuparse de cuestiones tan poco empresariales como la alimentación del obrero, su vestido, su limpieza, sus accidentes, los lugares en que vive, sus hábitos conyugales. Se ocuparán de su cuerpo, pues. Pero también de su alma, para mejor ocuparse de aquel; indagaran entonces sobre su instrucción y educación, sobre el empleo que hace de su jornal, sobre sus lecturas y diversiones, sobre sus virtudes y sobre sus vicios (Sierra 1985: 63)
\end{abstract}

Los discursos se traducen en prácticas de acción deliberada, es decir, en un dispositivo de control, que logra que los miembros de las familias industriales, se apropien de dichos discursos, identificándose en ellos. Con el tiempo construyen efectivamente arraigo en la población; los habitantes de los barrios ven pasar varias generaciones de sus familias en las industrias, construyendo sus propias historias al interior de ese microcosmos y sintiéndose coparticipes de la construcción de los espacios productivos y sociales.

\subsection{El giro espacial y las cartografías participativas}

En los años recientes la llamada explosión de la espacialidad en el campo de los estudios urbanos, las humanidades y las ciencias sociales, ha venido tomando un nuevo impulso en América Latina. Lo anterior, derivado preferentemente de la reinterpretación del trabajo de H. Lefebvre (2013) y del llamado giro espacial, desplegado por los actuales aportes de geógrafos como E. Soja (1997), en el mundo anglosajón, y A. Lindón (2008) en el contexto latinoamericano.

En los trabajos de E. Soja (1997), destaca su propuesta por una trialéctica del espacio, donde se discute con las miradas positivistas y sustancialistas sobre la realidad espacial, de la cual se desprenden perspectivas que refuerzan las concepciones estáticas y binarias sobre la vida urbana: lo subjetivo v/s lo objetivo, lo simbólico $\mathrm{v} / \mathrm{s}$ lo material, la significación $\mathrm{v} / \mathrm{s}$ la acción, la teoría v/s la práctica, el espacio $\mathrm{v} / \mathrm{s}$ el tiempo, etc.; enfatizando muchas veces una relación de subordinación de uno de estos polos respecto del otro. Soja propone por el contrario una epistemología del tercer espacio, esto es, que abarque simultáneamente lo social, lo espacial, y lo histórico. El tercer espacio, esto es, el espacio vivido, se traduce en un espacio empírico y experiencial, es decir, participativo y practicado en toda su magnitud por quienes lo habitan; pero al mismo tiempo es un espacio simbólico, emotivo, imaginado y material; biográfico e históricamente situado.

Lo anterior está posibilitando un retorno a las preguntas por la experiencia geográfica sensible y más cercana a las prácticas ciudadanas, que significan y producen activa e históricamente lo territorial, tomado distancia del denominado racionalismo geográfico.

Lindón aborda estas experiencias a partir de la categoría de subjetividad espacial, asumiendo 
al espacio no como un contenedor pasivo e inerte (como soporte exclusivamente físico), sino como vivencia ${ }^{4}$ o experiencia que se realiza cotidianamente y se genera en el devenir constante del uso concreto del espacio y su simbolización. Esta concepción experiencial y narrativa del espacio implica un ensamble entre el plano material (físico), el plano biográfico (subjetivo) y el plano socio-histórico (estructural). Así, las narrativas de vida espacializadas serían “(...) un relato organizado y secuencializado espacio-temporalmente de experiencias vividas por el sujeto en ciertos lugares (...) Otras veces corresponden a experiencias vividas por el narrador en un conjunto de lugares que van articulándose entre sí por las experiencias mismas o por la biografía del narrador" (Lindón 2008: 20). De ahí la necesidad de avanzar en el uso sinérgico de estas tres dimensiones, permitiendo desafiar el predominio de los enfoques unidimensionales y binarios sobre la vida urbana, re-instalando con ello la experiencia y el diálogo con los saberes cotidianos, en tanto antídoto para el conocimiento abstracto y deslocalizado.

De este modo asumimos a los mapas participativos y de co-construcción colectiva, como un espacio intersubjetivo y ciudadano que posibilita la activación de la conversación social, el encuentro y la interacción con otros/as, la actualización de las memorias colectivas, con el propósito de intercambiar ideas, visiones y experiencias concretas sobre los territorios que se habitan, sus problemáticas, sus fortalezas, sus historias y su devenir. Por esto, junto con el colectivo argentino Iconoclasistas, que se acopla a la tradición de pensamiento expuesta

Ver Di Meo, G. 1991. L'Homme, la société, l'espace. Paris: Anthropos. hasta aquí, entendemos al mapeo colectivo como:

(...) un medio, no un fin. Debe formar parte de un proceso mayor, ser una estrategia más, un medio para la reflexión, la socialización de saberes y prácticas, el impulso a la participación colectiva, el trabajo con personas desconocidas, el intercambio de saberes, la disputa de espacios hegemónicos, el impulso a la creación e imaginación, la problematización de nudos clave, la visualización de las resistencias, el señalamiento de las relaciones de poder, entre muchos otros (Iconoclasistas 2013: 13).

\section{2. Áreas de estudio}

Como podemos apreciar en la Imagen 1 las dos localidades estudiadas se encuentran en la actual Provincia de Concepción.

\subsection{La industria carbonífera en Puchoco- Schwager}

En el siglo XIX la creciente demanda del carbón, proveniente de las fundiciones de cobre, del ferrocarril, de la navegación a vapor y del alumbrado a gas, dio lugar a las primeras explotaciones de carbón en la zona de Concepción. La Compañía Carbonífera y de Fundición Schwager fue fundada en el año 1892 por el empresario de origen alemán Federico Schwager ${ }^{5}$, concentrando la explotación en los chiflones inclinados bajo el mar.

\footnotetext{
La explotación del carbón en el sector Puchoco de Coronel comenzó unas décadas antes bajo la dirección de Jorge Rojas Miranda y del mismo Federico Schwager asociado a Guillermo Gibson Délano en 1857. Mayor información en Mazzei, L. 1997. "Los británicos y el carbón en Chile". Atenea, Revista de Ciencia, Arte y Literatura 475: 137-167.
} 
Imagen 1. Mapa el ‘Gran Concepción’
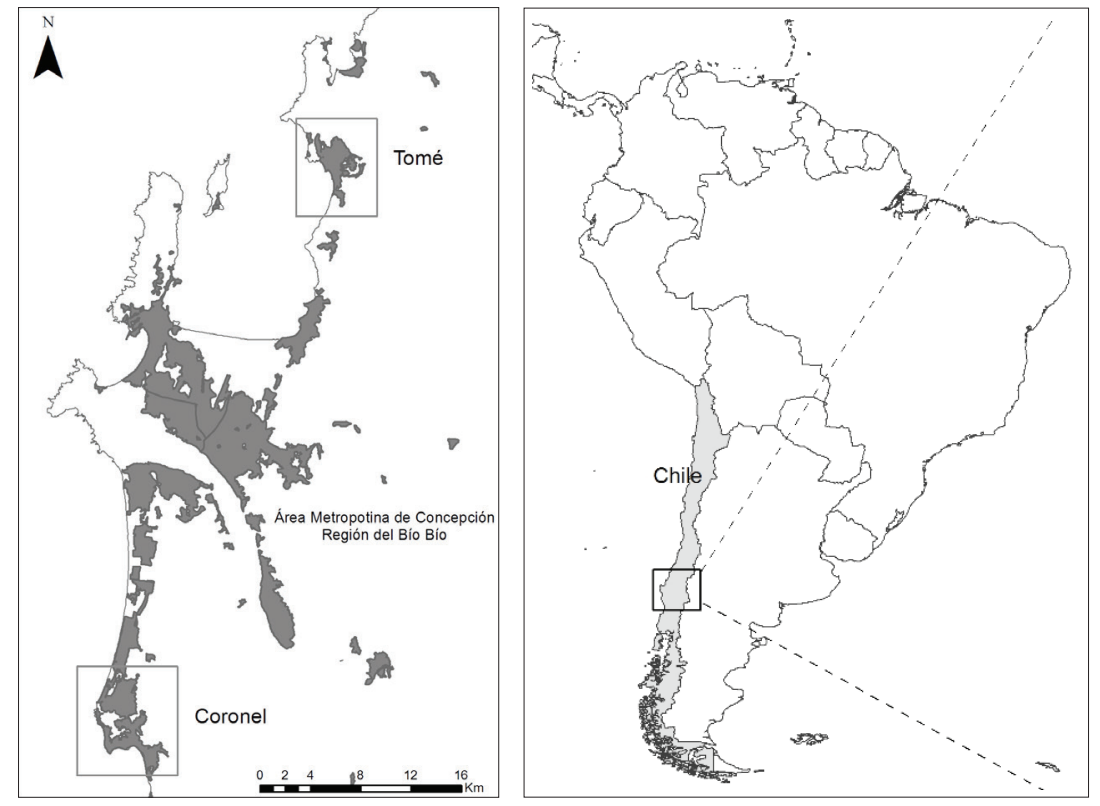

Fuente: Elaboración propia

El desarrollo carbonífero del sector Puchoco, transformó el paisaje, no sólo por la instalación de la faena productiva, sino también por la construcción deviviendasyequipamientourbano para sus trabajadores. Con la prolongación de la línea de ferrocarriles hacia el sur del Biobío (1872), el poblamiento de Schwager adquirió mayor fuerza; en el año 1877, se construyeron los primeros pabellones ubicados alrededor de la mina Puchoco, en 1892 se une al sector de Maule, creciendo hacia el sector Palomares en 1914. Entre 1920 y 1950, Puchoco se configura como una ciudad industrial (Pérez 2008).

Las primeras viviendas fueron pabellones residenciales, que contaban con lavaderos, hornos y servicios higiénicos colectivos. En 1928, fueron edificados nuevos pabellones para obreros y, en 1930 pabellones destinados al personal técnico. En 1939 comenzó la construcción de casas para el personal técnico y en 1941 para los celadores (guardias civiles de la empresa). Así, se segmenta y estratifica el espacio, el sector bajo para obreros y en lo alto del cerro los empleados y técnicos. Los edificios de servicio comunitario estaban ubicados en la parte baja, pero separados de la zona residencial por la línea férrea. En relación al equipamiento urbano en 1920 se construye el Economato y el retén de carabineros; en 1930 la plaza y, junto a ella, el mercado; la Escuela Industrial Federico Schwager, además de tres escuelas fiscales 
primarias para obreros (números 13, 14 y 16), en terrenos de la empresa y para los hijos de los empleados, la Escuela Particular № 6 (Díaz 1962: 50). En 1935 se construyó la Iglesia Jesús Obrero, el Gimnasio en 1950, el casino para mayordomos en 1949. El Servicio Social era muy importante para las políticas paternalistas de la empresa las cuales se instalan en los mismos barrios obreros; ya en 1953 se han expandido a 5 sectores de Coronel.

A mediados de la década de 1940, se construyeron las últimas viviendas proporcionadas por la Compañía a sus trabajadores, el Colectivo Chollín en Puchoco. La edificación de estos edificios de departamentos de arquitectura moderna, respondió a la mayor demanda por habitaciones, tras el terremoto de 1939 y a la apertura del nuevo pique Arenas Blancas (1942) (Fuentes 2012). Primero se construyeron tres bloques residenciales (dos para obreros y empleados con familia y uno para los obreros solteros), además espacio para el Apostolado Popular.

En 1958, comenzó a acelerarse el proceso de decadencia de la empresa. Producto de los altos costos de la producción del carbón y la baja demanda del mismo, en el año 1964, la Compañía Carbonífera y de Fundición Schwager se fusionó con la Compañía Carbonífera de Lota, dando origen a la Compañía Lota-Schwager S.A. En el año 1970 se estatizaba la Compañía, cuya propiedad pasaba a manos de la CORFO; más tarde, se fusionarían todas las minas del carbón, conformándose la Empresa Nacional del Carbón S.A. (ENACAR). El panorama para la industria del carbón no mejoró. Hacia fines de los años ochenta comienza el cierre de las minas, el definitivo se produce 1994 después de un accidente por gas grisú en Arenas Blancas donde murieron 21 trabajadores.

\subsection{La industria textil de Bellavista-Tomé.}

La Fábrica de Paños Bellavista Tomé fue creada en el año 1865 por el empresario norteamericano Guillermo Gibson Délano, quien ya había formado parte de una sociedad dedicada a la explotación de molinos en el sector Bellavista (Lagos 2009). Con la crisis de exportación de trigo, Délano decide cambiar su giro, fundando la industria textil (Becker et al. 2010). Con posterioridad a la muerte de su fundador, la fábrica fue vendida en reiteradas ocasiones hasta que fue adquirida por el empresario Carlos Werner, quien asume como único dueño a partir de 1912.

Werner quiso hacer de Bellavista un verdadero poblado industrial, no sólo con viviendas para los trabajadores sino también con diversos servicios destinados a satisfacer las necesidades de la comunidad. La primera población destinada a los obreros fue la Rana, que contaba con cuatro pabellones, lavaderos comunes y baños fuera de las casas (Cartes et al. 2012). Entre los años 1915 y 1920, se construyeron los pabellones obreros de Avenida Latorre; más tarde, el pabellón Chorrillos (1920) y el pabellón Miraflores (1934), ambos con sus lavaderos comunes y cocina fuera de las habitaciones principales. A partir de la década de 1920, se construyeron las primeras casas para los empleados, ubicadas frente a la playa Bellavista. Junto a las viviendas para obreros y empleados, se construyeron diversos equipamientos. Uno de ellos fue el retén de carabineros, en 1915 (Morales 2013); la Iglesia Cristo Rey (1923); el Chalet Caracol, residencia de Carlos Werner, que posteriormente albergó el Colegio Alemán para hijos de gerentes y jefes de la fábrica (1913); la Casa de Solteros (1915), que desde 1948 funcionó como policlínico y sala cuna. 
Con la muerte del empresario Carlos Werner (1926), se consolidaron las políticas de bienestar y el progreso de la fábrica, con nuevas construcciones; figura clave de esta etapa fue Roberto Schmutzer, Gerente General de la fábrica desde el año 1930. Él decidió comprar retazos de tierra en el interior del valle con el fin de construir viviendas para la creciente masa de trabajadores; así nació la población Florentina, construida bajo el modelo de pabellón obrero entre 1934 y 1944; la población "Los Cerezos" construida entre 1936 y 1965, destinada exclusivamente para los empleados con jefaturas, en su mayoría alemanes. El sector contó con diversos espacios públicos recreativos, como el Casino para Empleados (1948), piscina y cancha de tenis (1957) y parques y jardines. Finalmente, entre 1954 y 1957, se construyó la población "La Junta" que fue habitada por el personal administrativo de la fábrica.

También construyeron el Gimnasio Carlos Werner de Bellavista (1947), que en el segundo piso tenía un cine; la sede del Sindicato $\mathrm{N}^{\circ} 1$ de Bellavista (1949); la Maternidad (1940), la Casa Schmutzer (1942), dentro de la cual funcionó una biblioteca; el Mercado (1948), y una segunda pulpería (1950), la Estación de Ferrocarriles Carlos Werner (1954). En materia de educación, la Escuela E-420 de Bellavista, antigua Escuela $\mathrm{N}^{\circ} 3$, posterior al terremoto de 1960, fue trasladada al sector Florentina. Más tarde, nació la Escuela $N^{\circ} 1$ de Bellavista (Colegio Alemán).

El auge de las políticas paternalistas comenzó a decaer cuando los alemanes dejaron la administración; en el año 1962, el empresario Teófilo Yarur compra la fábrica, dando inicio a una época caracterizada por el descontento de los trabajadores y las constantes huelgas. El gobierno de la Unidad Popular decidió expropiar la fábrica, siendo ésta la primera empresa estatizada del país, terminando con más de un siglo de segregación social en los barrios.

Después del Golpe Militar, la fábrica quedó en manos de los militares (Agurto et al. 1976); unos meses más tarde, se llamó a licitación pública para la venta de la fábrica al sector privado. A través de una Cooperativa de trabajadores, constituida en 1974, los trabajadores ganaron la licitación y asumieron la dirección y administración de la fábrica; sin embargo, las duras limitaciones impuestas por la dictadura militar, hicieron imposible el fortalecimiento de la fábrica. La crisis económica de los ochenta llevó a la fusión de las fábricas textiles Oveja Tomé y Paños Bellavista. Finalmente, fue privatizada, en 1982.

\section{Aproximaciones cartográficas al espacio vivido de Puchoco-Coronel y Bellavista- Tomé}

A partir de los discursos de los habitantes actuales de los territorios fuimos generando una memoria espacializada, materializada en los mapeos colectivos, en la cual hombres y mujeres reconstruyeron sus experiencias como hijos e hijas y trabajadores y trabajadoras de las industrias.

Los mapas fueron categorizados por localidades rescatando aquellos aspectos que los propios habitantes fueron enunciando. En la Imagen 2 encontramos el mapa construido por los y las habitantes del sector de Bellavista en Tomé y en la Imagen 3 los de Puchoco-Schwager en Coronel. En la construcción de los mapas no 
hay reelaboración con fuentes secundarias que entreguen validez externa al ejercicio de memoria, sino que se utilizaron solo los datos entregados por nuestros informantes. Para el análisis se construyeron 4 categorías.

1- Los complejos industriales: aquí se reconoce la industria matriz y las asociadas, en el caso de Bellavista se reconocen la instalación del Molino, que fue la primera instalación de carácter industrial de la zona y que está asociada al carácter de puerto exportador de trigo que tuvo la zona, antes de constituirse como un conglomerado textil; también se reconoce la planta de Bellavista Oveja Tomé; la presencia de ferrocarriles, cuya estación representa un lugar de encuentro para los habitantes de la zona. Para Puchoco-Schwager se reconocen las industrias anexas (fábrica de ladrillos, gasómetro) y las instalaciones vinculadas al proceso de extracción del carbón (lavadora de carbón, planta jureles), pero no se localizan los piques mismos, esto por la naturaleza en la extracción del carbón, en mantos bajo la superficie.

2- Conjuntos Residenciales: aquí se localizan espacios habitacionales segregados por clase, están las casas de obreros y las de empleados. Llama la atención que para el caso de Bellavista las poblaciones aparezcan menos segregadas, hay una mezcla mayor en el espacio; en cambio en la zona del carbón solo aparece una instalación de empleados en el sector, esto porque la zona de empleados y técnicos se ubicó en un lugar distinto y exclusivo dentro del sector, la zona llamada Maule.

3- Equipamiento e infraestructura: aquí se marcan para ambos territorios el casino, gimnasio, teatro, cine, centro de salud (policlínico, maternidad, hospital), instalaciones deportivas, baños compartidos, sindicatos. En el caso de Puchoco se agregan los economatos y las oficinas de bienestar y de pago instaladas en los conjuntos obreros.

4- Espacios de relaciones sociales: en ambas localidades se relevan cuestiones comolas zonas exclusivas de jefes, de empleados y de obreros, la existencia de controles de segmentación por clase, los lugares de intercambio comercial, los lugares de diversión y los lavaderos. En Bellavista se localiza la huelga de 1966, porque constituye un hito relevante para los habitantes de la zona y en Puchoco se incorporan los hornos y los espacios comunitarios (Apostolado Popular entre otros).

\section{Narrativas del espacio vivido}

A partir del trabajo de campo con los mapeos colectivos y los relatos de los trabajadores/as, es posible identificar una organización y división social del espacio altamente segmentada y jerarquizada al interior de los barrios obreros estudiados. Pero simultáneamente se observan, particularmente para el caso de Bellavista, dinámicas de desacato en el espacio y formas colectivas de re-apropiación espacial.

Históricamente las industrias no sólo impulsaron un crecimiento sostenido de su productividad por la vía de la coacción física de los trabajadores y el disciplinamiento directo, sino que se hizo necesario que el trabajador voluntariamente internalizara el control social, no sólo dentro de las fronteras evidentes de la fábrica y los procesos productivos, sino también de modo más ubicuo y difuso, modelando los estilos de vida y colonizando la vida cotidiana de la clase 
Imagen 2. Mapeo Colectivo Residentes Históricos/as Bellavista-Tomé

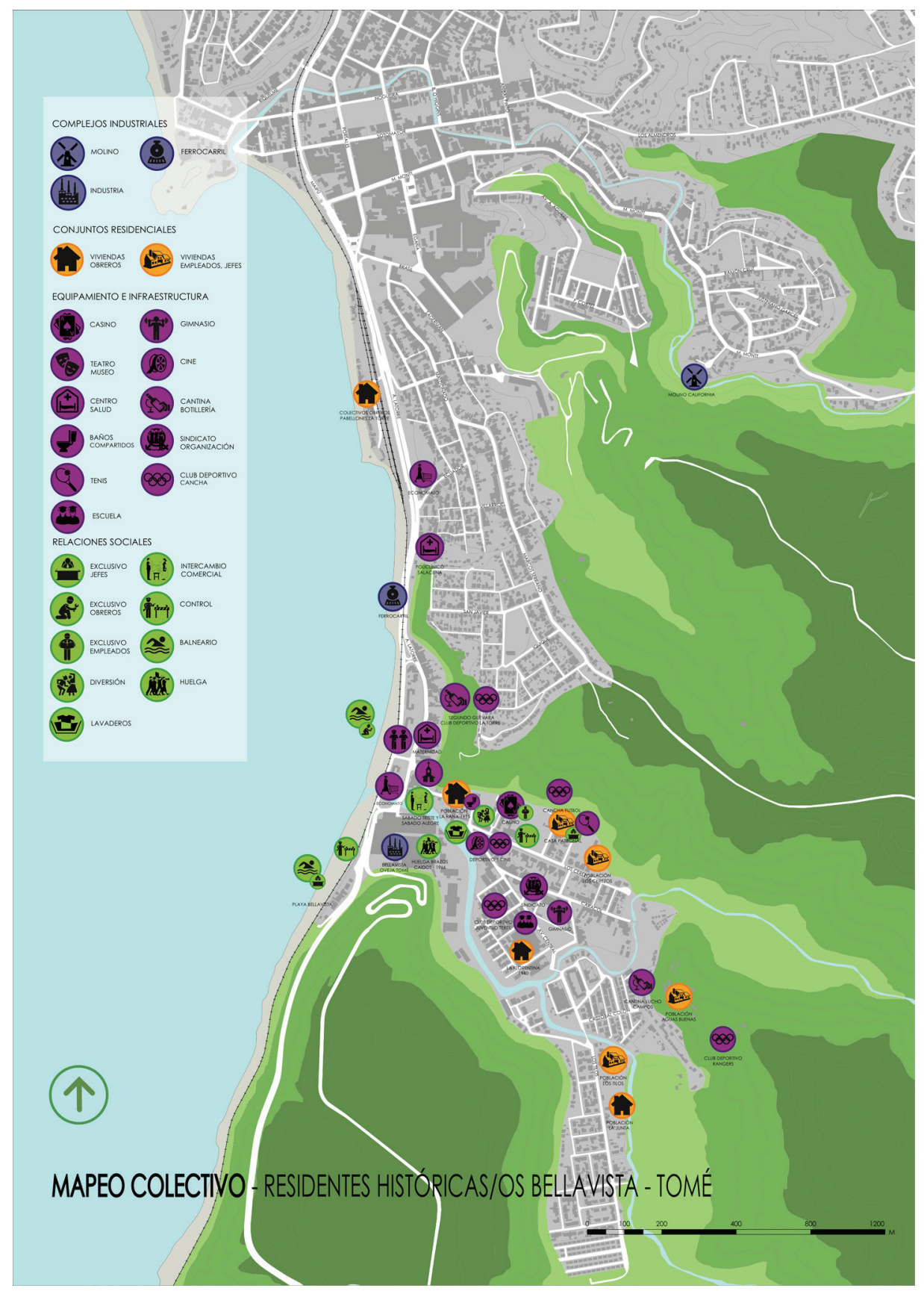

Fuente: Elaboración propia 
Imagen 3. Mapeo Colectivo Residentes Históricos/as Puchoco-Coronel

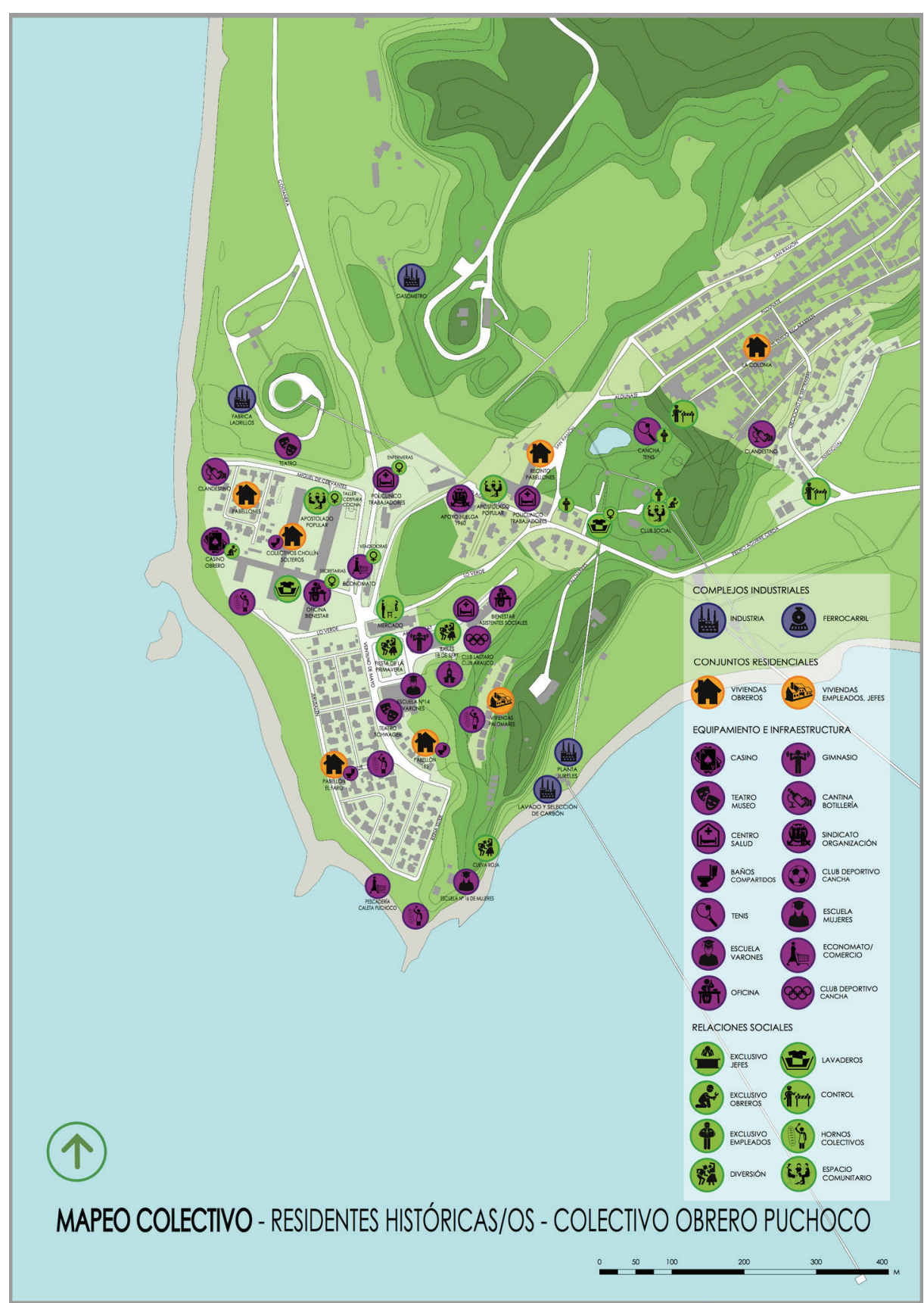

Fuente: Elaboración propia 
trabajadora, es decir, incluyendo tanto la esfera productiva como la reproductiva.

Entrado el siglo $X X$ las estrategias de vigilancia y coacción explícita, comenzaron a resultar insuficientes y menos eficaces que la combinación con modelos de control más simbólicos o de legitimación más cultural e ideológica. Dicha ampliación y extensión del modelo de corrección implicó innovar con un nuevo régimen de normalización de la fuerza de trabajo, que incluyó el diseño y colonización de los emplazamientos obreros, es decir, el diseño de sistemas de barrios obreros de nuevo tipo, así como la regulación y productivización de los espacios de ocio de los trabajadores y sus familias. Para autores como Foucault (1992) y De Gaudemar (1991) recién allí se instala históricamente la construcción gubernamental, de un tejido afectivo y socio-emocional entre capital y trabajo, un sentimiento corporativo que excede las fronteras de la industria, y cuya dominación supone un nivel de cooperación e internalización de la obediencia, o sea la legitimidad de la autoridad. Consecuentemente se garantiza una serie de beneficios sociales para los trabajadores orientados a impedir el reclamo y el desgobierno.

\subsection{La reproducción de la mano de obra}

Los habitantes de las poblaciones obreras construyen su memoria a partir del vínculo con la empresa, la que forma parte de todo lo conocido. Nuestros entrevistados/as trabajaron en las industrias, ingresando entre los años '50 y los '70. Ellos y ellas forman parte de un proceso que presenta como un único escenario posible y la mayor parte de las veces deseable - el formar parte de las industrias, que observaron desde que nacieron. Hay una tradición generacional, que los va anclando al territorio. Para ellos/as el trabajo en la fábrica o en la mina significaba estabilidad y un futuro conocido, conocían los sacrificios del trabajo, pero también conocían de los beneficios que podían obtener, de esa manera la empresa se encargó de asegurar un flujo constante de mano de obra.

\begin{abstract}
El carbón era el pan de cada día de todos los trabajadores, mis papás por ejemplo, yo me crié porque ellos trabajaban aquí. Mis abuelos, todos (Taller Puchoco).

Para mi Bellavista es mi segunda madre. De ahí comí antes de que yo naciera, porque mi mamá trabajaba y mi papá también trabajaba, así que cuando se alimentaban a mí también me alimentaban..., por lo tanto, yo soy hijo de Bellavista (Taller Bellavista).
\end{abstract}

El sentimiento que expresan evidencia las políticas explícitas de las industrias por generar las condiciones que le permitieran contar con la reproducción de mano de obra, fidelizada incluso antes de nacer. Se transformaba en el escenario de lo posible, aunque estaban conscientes de la vida de sacrificios, que para algunos no era lo que anhelaban dejar a sus hijos, pero era lo disponible, lo que otorgaba seguridad para el futuro

\footnotetext{
"El trabajo seguro era la mina. Los hombres, los hijos de obrero, siempre el papá se esforzaba para que el hijo no fuera igual que ellos, darle otra educación, pero si no podía había que caer al hoyito como le decían a la mina" (Taller - Puchoco).
}

\subsection{El espacio autosuficiente 'lo teníamos todo'.}

El mecanismo de aseguramiento de dotación constante de trabajadores/as, fue a través de las políticas de bienestar social, incluso mucho antes que estas fueran establecidas por la legislación nacional, así se lograba comprometer 
al trabajador/a con los destinos de la empresa. Era necesario entregar todo lo indispensable para la vida, por lo que construyeron casas, hospitales, escuelas, gimnasios, etc. La vida era entonces posible sin tener que moverse de los territorios; se transitaba de la faena productiva a la vida reproductiva, todo bajo la atenta mirada de las empresas que, bajo distintos dispositivos, lograban controlar todos los momentos en las vidas de sus trabajadores y sus familias.

Teníamos policlínico antes. Y una botica al ladito.

Esta lo más lindo que teníamos, el hospital que teníamos, un hospital de lujo.

Es que la empresa tenía todo eso manejado. Cualquiera no podía venir y vender acá, por algo tenían los negocios. Y ahí estaba uno fichado, porque uno pedía y lo descontaban por planilla. Mi mamá sacaba la harina, el azúcar.

Había desde una aguja hasta lo que usted buscara, ternos, ropa, zapatos, comida.

El teatro, acá teníamos muchas cosas. Era una ciudad chica. Teníamos el retén de carabineros, teníamos posta, teníamos oficina de bienestar, oficina de pago donde se pagaba la gente, teníamos lavadero, los hornos, teatro, gimnasio, teníamos una escuela básica que quedaba arriba donde ahora está el marino, que era la escuela 16 y la escuela industrial que está ahora, era la escuela 14 de hombres (Taller Puchoco).

Después tendríamos el gimnasio, la maternidad, que es de las cosas más antiguas.

Era de lujo esa maternidad. Y la mantenía con todos los profesionales y todo pagado por la fábrica. Tenía de todo, tenía matrona, tenía todo, igual que un hospital.

El policlínico también, es más antiguo.

Sala cuna, guardería y carabineros.

La escuela se construyó 1948 más o menos.

La empresa tenía un economato para su gente también, y eso quedaba al costado del retén de carabineros. Había una panadería también (Taller Bellavista).

A esta dotación de servicios se sumaba la preocupación en fechas especiales como fiestas patrias o navidad, desplegando la empresa la atención hacia los niños, haciendo partícipes a los miembros de las familias, del bienestar que la empresa entregaba:
Yo me acuerdo cuando de niño la fábrica para entregar para la pascua los juguetes tenía un camión, pero lo entregaba solamente a todos los que vivían en casas de la fábrica, los demás no (Taller Bellavista).

Lo bueno que había aquí en el gimnasio, lo bueno era que todos éramos niños no importaba que el papá fuera empleado o no fuera. Los juguetes para la pascua en el gimnasio, nos sentábamos en el gimnasio y pasaba el viejito pascuero y nos daban confites, galletas, naranjas (Taller Puchoco).

Para las familias vinculadas a las empresas, estas dotaron de todo lo necesario para vivir, y por lo tanto desde el recuerdo, muchas veces nostálgico, valoran positivamente esa experiencia en tanto se transforma en un sentido de pertenencia al lugar y sus vidas personales se inscriben en el devenir de la fábrica

\footnotetext{
La fábrica era muy buena. Para los dieciocho pintaban las casas lindas y nos regalaban empanadas a todos los de la casa (Taller Bellavista).

Todo, absolutamente todo. Yo abrí mis ojos y empecé a conocer y era todo de la empresa (Taller Puchoco)

La empresa quiso hacer de aquí, de Bellavista, la república de Bellavista (Taller Bellavista).
}

La experiencia de vida que tuvieron las familias que trabajaron en las industrias, se transforma en herencia generacional. A pesar de las dificultades que se vivieron, de los conflictos y tensiones permanentes, de la conciencia de la explotación y la discriminación de clase y de los innumerables conflictos laborales; hay una valoración positiva de la experiencia y ven con tristeza como desaparece, no solo la fuente productiva y el estilo de vida asociada a ella, sino también los vestigios materiales de los mismos

Cuando veo el Chiflón que lo destruyó [sic], tuvo que quedar como reliquia esa cuestión, porque eso nos dio la vida Claro, si el daño más grande es cuando botaron los pabellones, botaron el teatro que pudo haber quedado ¿Por qué no vendieron los pabellones? Así había quedado una reliquia que nos habríamos sentidos nosotros orgullos de Schwager (Taller- Puchoco) 
Una vez recuperamos un gimnasio para la comunidad, se recuperó el sindicato para la comunidad, son cosas que se podían perder y no pueden perderse. El patrimonio nacional tuvo que haber partido por esas cosas, el gimnasio, el sindicato y la maternidad, ahora es una casa que se cae sola, esas cosas tuvieron que haber sido salvadas como patrimonio, porque esa era parte de la historia de Bellavista (Taller- Bellavista).

\subsection{La vida cotidiana}

Para la eficacia de los procesos productivos instalados en zonas de poca población de carácter obrera, la primera preocupación fue fijar al trabajador/a, solo de esa manera se aseguraba estabilidad y productividad, por lo tanto una de las primeras medidas fue el dar habitación, de preferencia a la familia ${ }^{6}$. Las dos industrias analizadas entregaron casas a sus trabajadores/as, traspasando el uso -aunque controlado- de ellas, pero manteniendo la propiedad. Se entregan las condiciones mínimas de habitabilidad, que permitían la concentración y la reproducción de la mano de obra. Estas son empresas de larga data y es evidente que con el tiempo van avanzando en los servicios entregados y las personas recuerdan los hitos importantes, cuando tuvieron luz eléctrica en sus casas, o cuando se les construyeron servicios higiénicos al interior de las mismas. También cuando se comienzan a construir poblaciones más modernas con habitaciones

\footnotetext{
Es interesante el constatar que las políticas instaladas por las empresas estudiadas respondía a las estrategias de paternalismo industrial, que ven en la familia instalada el eje central, así lo expresa José Sierra: "En ese programa, en esa completa maquinación, todo se articula en torno a la vivienda. Lugar privilegiado de la reproducción, es también la matriz de algo importante, productiva y socialmente: la familia obrera... es la socia de la empresa, su otro yo...constituía un modelo disciplinario fácil y directamente utilizable por los ideólogos paternalistas (...) Únicamente asegurando la agrupación de los obreros en familias se estaba en condiciones de fijarlos... Porque en la familia empresarial el deber del trabajo [es lo único que] se hereda". (Sierra, 1985: 64).
}

más amplias y con mejores instalaciones, pero subsiste el recuerdo desde los primeros tipos de instalaciones, caracterizadas por ser habitaciones colectivas, de tipo pabellones.

Para donde yo vivía el pabellón estaba dividido en 5 casas para acá habían baños. El baño de los hombres, el baño de las mujeres, pero estaban dentro del mismo pabellón y tenía para ambas partes las salidas y las entradas, y dentro del pedazo había 5 espacios que eran baño y había un latón que se balanceaba y caía el baño, era como quien tira en la tasa del baño y día por medio le hacían aseo un caballero que le echaba un desinfectante" (Taller Puchoco).

Esa era de obreros y tiene una característica, que era el baño común. No había baños para cada casa, todos tenían que ir al mismo baño.

Tenía baños con agua caliente.

Hace poco, no hace mucho que se instaló el alcantarillado (Taller Bellavista)

Las viviendas entregadas, hasta el cierre de las fábricas, eran supervisadas directamente por los servicios de bienestar a cargo de las visitadoras sociales, quienes eran las encargadas de autorizar los arreglos necesarios, financiados por las empresas. Esto permitía que el costo de la vida para un trabajador/a de estas industrias fuese más bajo, ya que no pagaban la casa, ni ningún servicio o arreglo que se requiriera; esto era uno de los elementos que hacía que los habitantes de los territorios miraran siempre con anhelo el llegar a formar parte de esa familia.

Por ejemplo cuando se quebraba un vidrio venía la asistente social. Ella se encargaba de venir a los departamentos.

Se dejaban caer cada 15 días. Si había gente muy conflictiva las sacaban.

Venían a ver cómo estaban las casas. Un vidrio quebrado se cambiaba inmediatamente. No se podía ver basura. Los que eran antiguos, eso era lo que estaba bien preocupada la empresa del carbón (Taller Puchoco).

Llego luz, de todo, agua, alcantarillado, todos, no pagábamos, no pagábamos eso. La fábrica nos daba todo, todo, todo (Taller Bellavista). 
En el caso de Puchoco-Schwager el carbón no sólo era salario, sino que también formaba parte de la cotidianeidad, al ser usado como combustible, a los trabajadores se les entregaba para la cocina y la calefacción de las habitaciones. Además se construyeron lavaderos colectivos los cuales contaban con agua caliente y secadores para la ropa, con un sistema de calderas y con la dotación de personal para mantenerlos siempre en funcionamiento.

\footnotetext{
En el pabellón tenía la casa adentro una estufa grande donde se cocinaba el pan se hacía todo ahí y nos entregaban una cartilla y nos llegaba media tonelada de carbón y se metía a la carboné y eso era el combustible que teníamos.

Los lavaderos eran para las casas que no tenían lavadero. Y con agua calentita. Y llevábamos toda la ropa limpiecita y sequita.

Eran como dos fierros, así dos tubos largos y llevaban una puerta con un gancho y uno los abría para atrás hasta bien atrás. $Y$ ahí se colgaba las ropas (Taller - Puchoco).
}

Los beneficios que significaban tener una casa donde asentar a la familia y contar con los servicios de manera gratuita, hacía que el trabajo se cuidara, ya que el perder el trabajo significaba de manera inmediata perder esos beneficios. Un mecanismo para evitar esas pérdidas fue el traspasar dentro de la familia el trabajo, transformándose en una herencia, de la cual muchas veces no se podía escapar

Tenía que entregar la casa. Si se moría, si salía el dueño de casa muerto de la mina la viuda se podía quedar 6 meses más viviendo o trabajando en la empresa.

Así lo hizo mi suegra, se le murió el esposo que era minero y la pusieron a trabajar en el hospital de Maule y continúo viviendo en la casa.

Pero si morían de enfermedad natural, tenían que dejar la casa, irse y entregar la casa (Taller- Puchoco)

Podíamos vivir toda vida mientras trabajábamos. Una vez jubilado, sesenta días para dejar la casa. Entonces que pasaba, a mí me pasó, mis viejos jamás pensaron de que algún día iban a dejar de trabajar, entonces nunca compraron un terrenito, entonces qué pasó, que cuando los jubilaron justamente a los dos y yo tenía diecisiete años, tuve que entrar a trabajar para yo asegurar la casa, ellos tuvieron que vivir conmigo mientras tuve vida (Taller Bellavista).

\subsection{De segmentaciones espaciales y prácticas de desacato}

En cuanto a los emplazamientos de los casos de estudio, se observa que no se trata de asentamientos segregados al interior de un sistema urbano, o bien, de una ciudad o una comuna, sino que se observa un modelo urbano asociado con la llamada ciudad satélite, aislado de la gran ciudad, pero con un esquema autosuficiente y sustentado sobre sí mismo, de tal forma que en opinión de muchos de los participantes de los talleres los barrios se configuraban en una especie de república independiente (mercado, educación, iglesia, salud, vivienda, ocio, etc.). Lo anterior, permitía un aislamiento social con fuertes lazos de lealtad, pertenencia y solidaridad, una suerte de burbuja comunitaria, respecto de la influencia latente de politización y del estilo de vida más fragmentario.

Además, era posible identificar, particularmente para el caso de Bellavista, la proximidad entre grupos sociales de diversa procedencia. En algunos casos aparecen viviendas destinadas a grupos de solteros, o incluso grupos de profesionales, técnicos y jefes, coexistiendo en un mismo sistema junto con las viviendas para operarios. Lo anterior podría estar asociado con un efecto moralizante y de internalización de hábitos inter-clase. Aunque es evidente la jerarquización del espacio.

En ese plano destacan en el relato de los trabajadores, zonas de exclusión importantes. 
Para el caso de Puchoco en Coronel, estaba la zona de Maule, un barrio para los segmentos dirigentes y profesionales, situado próximo al asentamiento de Puchoco pero circunscrito fuera de su territorio más inmediato, lo que acentuaba su carácter exclusivo y excluyente. Para el caso de Bellavista en Tomé, estaba la zona de los Cerezos, que a diferencia de Maule se encontraba inserta dentro de un sistema más complejo de coexistencia entre las villas para obreros y las zonas de viviendas destinadas a los grupos dirigentes de la empresa. "Eso es Maule, ahí estaban las canchas de tenis. Había un casino de empleados. Acá había una comisaría, dos comisarías, una aquí y una en Maule. $Y$ a los pacos que se casaban, la empresa también les daba casa y a los profesores que trabajaban en los colegios. Había una cancha de tenis preciosa también (...) eran para ellos." (Taller Puchoco).

Para Puchoco, destacaba también un sistema de control de espacios públicos y áreas verdes, donde era posible identificar personal con funciones de vigilancia: "había disciplina. Era bien ordenado. En la plaza no se podía pisar el pasto. Había celadores que andaban cuidando y si pisaban el pasto le deban un huascazo" (Taller Puchoco). Para el caso de Bellavista, los Cerezos constituía una zona y un espacio privatizado, con controles de acceso de parte de personal competente, y con equipamientos exclusivos. "En los Cerezos vivían ahí todos los jefes alemanes, era recinto privado. Tenían hasta una garita ahí (...) era para los técnicos. Para los jefes y los dueños. Los alemanes. No entraba nadie que no conociera. Había piscina, cancha de tenis, para jugar bowling, pero era privado, para ellos no más" (Taller Bellavista)

La playa de Tomé es otro ejemplo interesante, donde se identifican áreas de distribución exclusivas para la gerencia y los grupos de profesionales vinculados con la industria y los grupos de operarios y sus familias. Esta división social del espacio estaba configurada por la frontera natural demarcada por el río, y también es posible reconocer funcionarios competentes para el desarrollo de funciones de vigilancia y control.

Porque había playa para pobres y para ricos en Bellavista, hay dos playas, del río para acá y del río para allá (...) tuvo que haber sido por el 1950. Nosotros no podíamos pasar del río hacia el sur (...) La playa del sur que era de los empleados y los jefes, le ponían 100 camarines con su llave respectiva (...) Nosotros, hijos de obrero, no podían entrar ni siquiera a esa playa, y pobre del que pasaba, porque el jefe de la población se ganaba arriba del puente y empezaba a mirar a todos los que pasábamos y los anotaban, y al otro día los acusaba con el jefe de personal (Taller Bellavista).

En los cines emplazados al interior de ambos barrios obreros se daban situaciones que también reflejaban lo altamente segmentado del espacio y su uso, denotando una suerte de microfísica del espacio que diagramaba relaciones de poder y una política en torno a la disposición de los cuerpos en el espacio, que reforzó implícitamente la internalización de la obediencia y la jerarquía social.

Acá la empresa también tenía un administrador. Y se encargaba de pedir la película para los trabajadores, ellos iban a buscar las películas para poner. Y le cobraban a la gente, en la boletería tenían galería y platea. Claro que nosotros teníamos que pagar la entrada. En el cine había discriminación, abajo en platea habían como 5 corridas más o menos de asientos con cadena a ambos lados. Esos asientos eran para los puros administradores y jefes de la empresa, nadie se podía sentar ahí. (...) Platea y galería. Platea era abajo. Llegaba un bus de Maule, para traerlos al cine y llevárselos (Taller Puchoco).

La empresa creó el cine de Bellavista (...) y ahí también se notaba mucho la discriminación, los obreros a un lado, los alemanes al otro y los empleados atrás. Digamos, los hijos de alemanes y las familias alemanas tenían las primeras butacas, y después venían los empleados, y al 
otro lado (...) otras butacas, sillas, estaban los operarios (...). Pero las butacas, no se podía sentar en las butacas esas bonitas de terciado (Taller Bellavista).

En oposición a lo anterior, se observan diversas prácticas de desacato, particularmente para el caso de Bellavista, en el contexto del gobierno del Presidente Salvador Allende, entre 1970 y 1973. Aquí los testimonios coinciden en un cambio radical de la sociedad y de los modos en que dicho cambio impactó las lógicas de organización de la producción y la forma de vida al interior de asentamiento obrero, particularmente la trasformación de los espacios y las zonas que antes aparecían como exclusivos o privatizados.

Cuando sube Allende al gobierno y cambia toda la historia, pero cambia tan brusca que como sacamos la barrera para poder entrar. Y claro, la administración de la fábrica dice no, ahora todos se pueden ir a bañar a la piscina y quedó la crema, porque no había disciplina en nosotros y nos fuimos a bañar en la piscina que se bañaban ellos. (...); lo que nosotros vivimos el 70 aquí, creo que pasó en todo Chile. Fue un despertar, una cosa que era algo distinto y que ahora que somos iguales y no éramos iguales, pero nosotros creíamos que éramos iguales y esa fue la cosa, yo creo, que hubo un cambio tan grande en Bellavista, porque como le explicábamos, todo aquí era privado. (Taller Bellavista).

Asimismo, los espacios tradicionalmente organizados para la producción y el orden, concretamente los espacios de la industria, fueron reutilizados en ciertos momentos como espacio festivos.

Fue en la etapa entre el 70-73 que hubieron fiestas dentro de la fábrica, que fue una revolución también, que fue una locura también (...), fueron para el 18 de septiembre, la fábrica no producía ese día y nosotros arreglamos cada uno sus secciones, todos los obreros y ahí la fábrica se ponía con las empanadas y los tragos y hacíamos una fiesta dentro de la fábrica, pero había de todo y sobraba de todo, era una fiesta que se hacía en la bodega grande y todo el espacio (Taller Bellavista).

\subsection{Deporte y ocio regulado}

Un componente central en el modelo paternalista que aquí revisamos se asocia con colonizar los espacios de ocio y el tiempo libre de los trabajadores y sus familias. Esta estrategia posee una doble función, por una parte mantener ocupados y alejados de los "vicios" a las clases trabajadoras, productivizando un espacio social que se naturaliza para los trabajadores como un tiempo de ocio y distracción, pero que en concreto se traduce en objeto de toda una economía política altamente rentable para la industria y para la elite dirigente que lo diseña y lo promueve en tanto forma de disciplinamiento difuso. Por otra parte, tiene como función la construcción de lazos y sentimientos de colaboración y solidaridad intra-clase e interclase, fortaleciendo el discurso paternalista, la pertenencia y la identificación con una gran familia representada por la industria.

Había un equipo de box por los clubes que estaban en Schwager. El Lautaro, el Arauco. Acá también como el gimnasio era para jugar basquetbol, había una selección de Schwager de basquetbol. También vino la selección Chilena a jugar acá (...) Así que la banda esta que le llamamos nosotros cada vez que había campeonatos de basquetbol acá, ellos estaban adentro. Tocaban, amenizaban ahí. También cuando jugaba la selección de Schwager, allá estaban en el estadio (Taller Puchoco).

Las tres industrias tenían equipos profesionales, en esa época eran semiprofesionales, que jugaban en el campeonato regional de Concepción, que jugaban profesionales y Tomé siempre lograba muy buenos puestos en el campeonato, entonces era un poco temido deportivamente, en el basquetball, en el box, en todos los deportes. Tuvimos muy buenos atletas, una de las que siempre veo la estatua de la chiquilla Peter, la Lisa y otros más. Boxeadores nacionales e internacionales, entonces había una actividad recreativa por un lado, participativa en el aspecto social, porque se hacían reuniones de baile, en fin y todos participaban, la familia. (Taller Bellavista).

Los espacios deportivos y de ocio en general se asocian con espacios desregulados y para 
el libre ejercicio recreativo de los trabajadores y sus familias, sin embargo en el contexto del paternalismo industrial obedecen a la optimización de la salud y al re-encausamiento de la actividad física en el extra muro de la fábrica y el hogar. También un medio que ejerce la elite dirigente para regular la actividad conspirativa de parte de la organización obrera. Cuerpos económicamente rentables y políticamente dóciles. "Esos son los puntos más importantes, porque ahí se arreglaban todas las cosas, en el sindicato se trataban los problemas de los trabajadores con la empresa y en gimnasio nos desahogábamos con los shows, los deportes, las películas, los bailes" (Taller Bellavista).

\subsection{Equipamientos valiosos y momentos memorables}

En general los testimonios de ambos grupos de trabajadores asociados con los dos casos analizados, tanto para el caso de varones como mujeres, coinciden en identificar a los equipamientos para el deporte y la recreación como los más valorados y rememorados en la historia que ellos mismos tejen sobre sus propios barrios.

En el caso del colectivo obrero Puchoco, se releva el rol del gimnasio y de economato. "El lugar como más importante sería el gimnasio $y$ el comercio (...) el economato, que es antiguo. Esas son las dos cosas que están acá en Schwager penando se podría decir, así destruidos. Resulta que es la fachada de Schwager" (Taller Puchoco). En el caso de Bellavista también destaca el gimnasio y las instalaciones de la compañía de bomberos, donde se realizaban eventos de tipo festivos.
Yo me acuerdo que cuando chico los bomberos hacían una fiesta muy hermosa, pero inolvidable aquí en Bellavista y en Tomé, incluso en la región, la cuarta compañía de bombero que pertenecía a la fábrica, hacia una especie de carnaval una vez al año, hacia una elección de reina y hacia un baile pero que lo hacía en todo el gimnasio, traía como a 200 personas, a dos orquestas (...) Estamos hablando del 50 para adelante (...) era una fiesta con todos elegantes, todos bien vestidos (Taller Bellavista).

Sabe usted que este gimnasio para los trabajadores, para todos en realidad. Todas las semanas lleno el gimnasio, jugaba cualquier equipo, lleno. Cuando habían competencias de box intersecciones también. Se llenaba. De Basquetbol igual. Era la entretención para la gente. No tenían mucha más diversión, era un desahogo. Además venia Petrox cuando estaba en Dimayor, el Naval. Aquí vino los Globe Trotters a Tomé, una 600 personas. Fueron como 800 y tantas personas; cuando había peleas de box se llenaba, solo quedaba el ring y había como 700 personas (Taller Bellavista).

\subsection{Producción de espacios de sociabilidad}

Entenderemos por espacios de sociabilidad e intercambio social a aquellas geografías que se generan por las dinámicas que ponen en juego espontáneamente los propios actores sociales en el espacio, y que de alguna forma implican procesos de re-apropiación y co-construcción de territorialidad, donde la topofilia y la carga emocional que los sujetos le adjudican al espacio cumple un rol preponderante para su conformación. En el marco de los talleres que se implementaron esta dimensión se explicitó particularmente en el caso de Bellavista en Tomé, donde se identificó a: la Estación de Trenes; la playa; y a las cantinas o bares de uso masculino.

La Estación de Trenes como un espacio público, un espacio de intercambio privilegiado y donde se escenificaba la pertenencia y de orgullo:

Todas las tardes las familias se juntaban en la estación de Tomé, que era bastante larga, era embaldosada y tenía techo. Yo admiraba algo y que era que hasta en invierno 
la gente iba a pasearse en la estación, muchas veces para esperar a familiares que trabajaban en Concepción (...) y ahí había una actividad social de saludarse (...) los encuentros en la tarde también, en la plaza, pero lo que yo admiraba era que todo el mundo bien vestido, era como un encuentro, decir yo soy de FIAT, yo soy de Oveja, yo soy de Bellavista, era algo muy socialmente hermoso (Taller Bellavista).

La playa como un espacio hecho suyo, reapropiado y colonizado para compartir, autoafirmarse y distinguirse frente al resto de los habitantes:

La playa era un lugar de encuentro, al tenerla acá en frente. Era un lugar de encuentro para todas las personas de Bellavista, porque esta playa la consideramos nuestra, era considerada de la gente de Bellavista, no porque nos apropiamos de la playa, sino porque la gente tomecina no venía para acá, para ellos era más importante ir a la playa del Morro y Dichato; y esta la consideraban una playa cualquiera, por eso la hicimos propia la gente de Bellavista (Taller Bellavista).

El lugar de encuentro de los trabajadores viene de muy atrás, donde habían expendios de bebidas alcohólicas. En esos lugares estaban los trabajadores. Pasaban de la fábrica a servirse algo. Por ejemplo era muy popular (...) en ese tiempo se Ilamaba don Segundo Guevara. Nosotros los de Latorre nos juntábamos siempre ahí (...) Y ahí uno se iba a tomar su copetín, porque tenía rayuela y ahí se compartía con todos los amigos. $Y$ al final todos nosotros nos juntamos y formamos un deportivo, el deportivo Latorre. Salió de todos los amigos. Eso fue en el año 50 (Taller Bellavista).

\section{Conclusiones: el claustro y el horizonte como formas de habitar}

En primer lugar, para los dos casos analizados, queremos destacar que a partir de los primeros años de la configuración de los barrios, comienza un poderoso impulso de parte de la empresa a toda actividad que involucre, a los trabajadores y sus familias, con la vida sana y el deporte en sus diversas expresiones, promoviendo la construcción de infraestructura para la materialización de actividades deportivas y de esparcimiento. Lo anterior incluyó canchas, gimnasio, estadios, etc. De igual forma, se generó una importante cobertura de la empresa para que la comunidad participara y se integrara en las actividades festivas, como los bailes en la compañía de bomberos o en el gimnasio. $Y$ también un amplio y sistemático acceso al cine y su imaginario translocalizado. Como lo venimos planteando, lo anterior da cuenta de una política de control social en el extramuros de la industria, una concepción de lo gubernamental que subsumió tempranamente al tiempo libre en una lógica de productividad biopolítica, donde lo central está en la acumulación de la fuerza, el incremento de la vida y la promoción de lo saludable en las poblaciones humanas. De ahí que postulemos que la gestión de ocio de las clases trabajadoras en el contexto del paternalismo industrial, responde a un correcto encauzamiento del tiempo libre, toda una moral del ocio, pues no estamos en presencia de un gasto superfluo, o un tiempo libre sin rentabilidad, sino de una corrección ubicua de la energía desplegada en el plano de la vida cotidiana de los operarios y sus familias, toda una economía política del tiempo libre.

Por esta razón, el espacio de ocio de las clases subalternas tuvo que ser regulado y modelado, no podía dejarse al azar de los dados y las cartas, de lo opaco y lo furtivo, sino que se comprendió -estratégicamente- que para construir hegemonía de parte de la clase dirigente, ya no era posible sólo integrar a los operarios por la vía del salario, sino también por medio de un poder simbólico y afectivo; toda una película de legitimidad cultural. Allí el ocio se constituyó en un espacio altamente rentable para las clases dirigentes. $Y$ eso no fue automático, sino que decantó y se sedimentó -socio-históricamente- 
luego de un largo periodo de vigencia de lógicas productivas más represivas y coercitivas.

Pero no todos los hallazgos se vinculan con procesos de subordinación y controles más explícitos o difusos, sino que también es posible identificar dinámicas creativas de coconstrucción de territorios cotidianos por parte de las comunidades de trabajadores/as. De alguna forma este campo de dinámicas está fuertemente vinculado con lo que Lefebvre llamó los espacios de representación ${ }^{7}$, es decir, espacios vividos que se desmarcan imaginativa y simbólicamente, pero también relacionalmente, de los encuadres dispuestos por el poder, o por quienes diseñan, definen y construyen materialmente la infraestructura urbana. También podemos llamarlos signos de re-apropiación del espacio, que re-crean mediante usos heterogéneos de los emplazamientos, una geografía emocional que la hace especial y cotidiana para el grupo humano que la co-construye activa y participativamente en el tiempo. Aquí destacamos entre varias de estas geografías a dos de las más significativas. Por un lado, la Playa de Tomé, específicamente a la zona utilizada y vitalizada por los operarios vinculados a la industria Bellavista. Por otro lado, la Estación de Trenes en Tomé, en tanto espacio público, pero no en el sentido ilustrado del ciudadano clásico, o del ágora, sino de un espacio público cotidiano y de copresencia para la escenificación de un orgullo colectivo, un patrimonio cultural y un paisaje identitario, expresado en ser parte de un estilo de vida urbano, como señalan ellos mismos: la comunidad de familias de obreros mejor vestida del país, una forma de habitar ese fragmento de mundo llamado por ellos: República de Tomé.

Consultar: Lefebvre, H. 2013. La producción del espacio. Madrid: Ed. Capitán Swing.
Los dos territorios analizados tienen en común haber sido creados en la segunda mitad del siglo XIX y tener una historia de funcionamiento de más de un siglo, por lo tanto la memoria de los trabajadores/as está viva y la presencia de las empresas aún permanece. Las casas donde viven fueron construidas por las industrias y todavía es posible recorrer los vestigios materiales de lo que fue su época de mayor esplendor. Existe un sentimiento de arraigo en el espacio y valorización de la empresa, se reconoce al paternalismo industrial, sin desconocer sus prácticas de segmentación y explotación. Los trabajadores valoran el que las empresas permitieron constituir un espacio autosuficiente y totalizador de la experiencia social, era -emulando su propio relato- una república independiente. Esto hace que los habitantes de los barrios sientan en la actualidad que una vez cerradas las empresas se quedaron sin nada, por eso hay una nostalgia con el tiempo pasado. Aquí se producen diferencias en ambos territorios ya que en PuchocoSchwager, el pasado es solo añoranza del trabajo seguro, pero hay un sentimiento de que el barrio no tiene futuro, hay desesperanza, a lo cual se suma en la actualidad una alta cesantía comunal, problemas medioambientales, migración de jóvenes, etc. En cambio en Bellavista, la empresa aun funciona, y aunque en una escala muy reducida (después de la quiebra en el 2007), todavía creen que es posible reabrirla y se considera como la única solución a los problemas de cesantía y la falta de proyección de la comuna. Asimismo, se percibe un sentimiento de mayor esperanza, lo cual implica la circulación de mayores activos culturales vinculados al patrimonio industrial, como motor de identidad, que se manifiesta en un sentido de orgullo de pertenecer al territorio, reapropiándose de su espacio e historia. 
En ambos territorios existe un sentimiento corporativo, que implica de alguna manera una reapropiación del modelo del paternalismo industrial, porque hicieron suyo el estilo de vida y la propuesta valórica, el cual se sostiene hasta el día de hoy a partir de la circulación de afectos y memorias en torno a los vínculos y la materialidad que los rodea. Sin embargo, hay diferencias entre los dos espacios, marcadas por el paisaje, transformado en experiencias, en subjetividades que circulan; lo que a nuestro juicio puede resumirse en la idea de lo abierto y lo cerrado, que implica una mirada del horizonte distinta.

Por una parte, hay una valoración diferente del mar, de la playa (ambos emplazamientos ubicados a orilla de mar). En Bellavista el mar representa apertura, un horizonte abierto, es reconocido como un espacio de ocio y disfrute, un lugar de encuentro de los jóvenes, pero también de la familia. Por otra parte, en Puchoco, el mar representa límite, una frontera que encierra, el mar es espacio productivo, da de comer. Muchos mineros cuando no estaban bajo el mar extrayendo carbón, estaban sobre él extrayendo recursos para su alimentación y subsistencia, se construye un vínculo más cercano con deber, el esfuerzo y la necesidad. El territorio está marcado por el dolor y el sacrificio, ya que los hitos que más se recuerdan son los vinculados con los accidentes y las muertes de los mineros. La memoria está teñida por la oscuridad de la mina y por el color negro del carbón, el que impregnaba sombríamente los cuerpos de los mineros una vez que salían a la superficie, marcando de manera trágica el tránsito entre subterra y subsole ${ }^{8}$, una memoria

La utilización de los conceptos subterra y subsole son tomados de la obra literaria de Baldomero Lillo, quien a comienzos del siglo XX narra historias de obreros del carbón (Subterra) y vidas y costumbres populares de origen campesino en (Subsole). del dolor, acentuada por la sensación de claustro que sigue teniendo el sector y la comuna.

En cambio en Bellavista, hay una memoria más conectada con el goce, que recupera el componente festivo de la experiencia social (como la celebración de los 100 años de la empresa en 1965), la importancia histórica de haber sido visitados por el presidente Allende durante la Unidad Populary haber sido la primera empresa estatizada del país; hay un sentimiento de ser modernos, ellos se reconocen como los obreros mejores vestidos del país, porque se visten con el mejor paño del mundo, el de la fábrica Bellavista, que regalaba anualmente telas para el trabajador/a y sus familias. Su producción simboliza color y modernidad, moda y estilo, y ellos se integran festivamente a ese universo simbólico.

Diferente es también la memoria de los dueños de las empresas y sus prácticas de paternalismo a partir de la presencia en la vida cotidiana de los sujetos. En Puchoco no se mencionan, pareciera ser que la gente no los recuerda, no sabe siquiera quienes son, como eran. En cambio en Bellavista hay un recuerdo personalizado del tiempo cuando los alemanes eran dueños de la empresa, como dice un ex-trabajador, recordando a uno de sus jefes alemanes "Entré a maestranza y yo me di cuenta con mi jefe, de él aprendí todo, lo que soy hoy día de verdad lo aprendí ahí", él recuerda que se sentaba con ellos y le decía "no, eso no me gusta, el ser humano tiene que alimentarse con un vasito de leche, unas galletitas, un sándwich, pero no con esto...se van a enfermar y nos empezaba a explicar..." (Taller Bellavista). En cambio en Coronel, no existe cercanía, fundamentalmente porque no se mezclan en el proceso productivo, y se genera vida cotidiana separada. 
El paternalismo y su batalla de moralización, es a nuestro juicio y por sobre todo, más que una batalla disciplinadora y normalizadora, una tarea de seducción y cooperación, una estrategia de colonización ideológica y cultural, la cual concluye con un obrero que tiene acceso a parte de la modernidad, por lo tanto, es más responsable y tiene capacidad para comprender procesos más amplios; no es solo la brutalidad del trabajo, tampoco el ocio es una práctica de pan y circo. El producto es un obrero moderno, soñado, que tiene capacidad de trabajo, y que sabe auto-regularse en los espacios de ocio saludable y consumir cultura en un sentido amplio. No obstante, estos procesos no estuvieron ausentes de fricciones y conflictos, pues hacerse modernos también implicó crecer en organizaciones de clase y para la clase, aunque las herramientas culturales del paternalismo tuvieron históricamente un papel capital en la contención y gestión de dichas tensiones.

\section{Bibliografía}

Agurto, A., Ortiz, G. y Torres, D. 1976. Sistematización del ciclo tecnológico en el área cooperativa. Cooperativa de Trabajo Paños Bellavista Tomé. Informe para optar al título de Asistente Social, Universidad de Concepción.

Becker, E., Pérez, S., Saavedra, M. y Saldías, E. 2010. Bellavista. Memoria Oral de un pueblo industrial. Concepción: Consejo Nacional de la Cultura y las Artes, Fondart Creando Chile.

Cartes, A., Luppi, R. y López, L. 2012. Bellavista Oveja Tomé. Una fábrica en el tiempo. Concepción: Ediciones Universidad San Sebastián.

De Gaudemar, J. 1991. El orden y la producción. Nacimiento y formas de la disciplina de fábrica. Madrid: Editorial Trotta.

Di Meo, G. 1991. L'Homme, la société, l'espace. Paris: Anthropos.

Díaz, M. 1962. Labor del Servicio Social en las Compañías Carboníferas de Lota y Schwager en el año 1961. Memoria de Prueba para Asistente Social, Universidad de Concepción.

Fuentes, P. 2012. "Hibrido y vanguardista, del familisterio al condensador social. El colectivo Chollín como arquetipo moderno". Patrimonio e Paisagem em espacos lusófonos e hispanicos. Tendencias e projecoes: o futuro aquí e agora. Gazzaneo, L. (Editor). Río de Janeiro: Universidade Federal do Rio de Janeiro, Colecao Proarq. 101-121.

Foucault, M. 1992. Genealogía del Racismo. Madrid: Ed. La Piqueta.

Iconoclasistas. 2013. Manual de mapeo colectivo: recursos cartográficos críticos para procesos territoriales de creación colaborativa. Buenos Aires: Tinta de Limón.

Lagos, K. 2009. Evolución urbana del barrio industrial Bellavista. Seminario de Título de Arquitectura, Universidad de Concepción.
Lefebvre, H. 2013. La producción del espacio. Madrid: Ed. Capitán Swing.

Lindón, A. 2008. "De las Geografías constructivistas a las narrativas de vida espaciales como metodologías geográficas cualitativas". Revista da ANPEGE 4: 3-27.

Lindón, A. 2007. "El constructivismo geográfico y las aproximaciones cualitativas". Revista de Geografía Norte Grande 37: 5-21.

Lindón, A. 2006. "De La Geografía Humana: Un camino a recorrer". Tratado de Geografía Humana. Hiernaux, D. y Lindón, A. (Editores). Barcelona: Anthropos-UAM-I. 1-22.

Lindón, A. 2006. "La Geografía de la vida cotidiana". Tratado de Geografía Humana. Hiernaux, D. y Lindón, A. (Editores). Barcelona: Anthropos-UAM-I. 356-400.

Mazzei, L. 1997. "Los británicos y el carbón en Chile”. Atenea, Revista de Ciencia, Arte y Literatura 475:137-167.

Morales, D. 2013. El paternalismo industrial en la Fábrica de Paños Bellavista, 1910-1935. Tesis Magister en Historia, Universidad de Santiago de Chile.

Pérez, L. 2008. "El barrio Puchoco en Schwager. Cuando la industria construye el paisaje cultural”. Urbano 16 (11): 47-58.

Salazar, G. 1985. Labradores, peones y proletarios. Formación $y$ crisis de la sociedad popular chilena del siglo XIX. Santiago de Chile: SUR Ediciones.

Sennet, R. 1982. La autoridad. Madrid: Alianza Editorial.

Sierra, J. 1990. El obrero soñado. Ensayo sobre el paternalismo industrial (Asturias, 1800-1917). Madrid: Siglo XXI Editores.

Sierra, J. 1985. "Política de vivienda y disciplinas industriales paternalistas en Asturias", ERIA Revista Cuatrimestral de Geografía: 61-71.

Soja, E. 1997. "El tercer espacio. Ampliando el horizonte de la imaginación geográfica". Revista Geographikós 8: 71-76. 
